\title{
Preliminary Study on Establishing the New System of Assessment and Evaluation of "Athletic Physiology”
}

\author{
Liu Qian \\ Department of Sports, College of Arts and Sports, Sichuan Agricultural University \\ Ya'an 625014, Sichuan, China \\ E-mail: lydia2000@yeah.net
}

Foundation Item: Periodical achievement of the educational reform project of Sichuan Agricultural University "establishing the new system of assessment and evaluation of 'athletic physiology' with a combination of theory, design and application" (Foundation NO. X2011040)

Received: April 4, 2012 Accepted: April 16, 2012 Online Published: May 2, 2012

doi:10.5539/hes.v2n2p72

URL: http://dx.doi.org/10.5539/hes.v2n2p72

\begin{abstract}
In the light of the problems existing in assessment of the course of "athletic physiology" in universities at present, this article makes reflections upon the assessment mode of students for this course and takes a general survey on development of the evaluation system by comprehensively employing both the quantitative method and qualitative method. By taking into consideration of educational evaluation, it focuses on diversification, process, development and practice and sets up a set of new system of assessment and evaluation with combination of "theory, design and application", which is of great significance to promote curriculum reform of "athletic physiology", improve teaching quality and exam style and learning style as well as fulfill the teaching goal of the course.
\end{abstract}

Keywords: Athletic physiology, Assessment of students, Evaluation system, Educational evaluation

\section{Introduction}

"Athletic physiology" is one of the backbone courses in sports faculty in universities and it has an extensive scope of knowledge in that it not only overlaps with anthropotomy and histology, but also involves morbid physiology, molecular biology and sports biochemistry, etc., with quite abundant content and strong theory, so it is relatively difficult for students to learn. Thus, the assessment and evaluation system of this course is supposed to have its own complexity and particularity. In the meanwhile, the course of "athletic physiology" has strong practice and applicability, so it is the basis to guide the nationwide fitness and scientific athletic training and its quality of teaching is closely bound up with the capacity of sports educators in the future. However, the teaching content of "athletic physiology" is complex and it has always been a course of headache to students majoring in sports in universities and students generally feel tedious and insufficient of interest. Especially, in the past few years, with continuous proceeding of teaching reform in universities, the teaching hours of this course have been obviously reduced and both teachers and students feel great pressure in the process of teaching. Teachers inculcate a theory in a cramming way in the class and students cram for the coursebook prior to the exam, in which both teachers and students are at a passive state. In addition, the content of the course is abstract and difficult to understand and students are likely to lose the interest and enthusiasm in learning this course so that they may be weary of studying and even be absent from the class, which is indeed worrying. There are quite a lot of causes for occurrence of this phenomenon, among which the traditional assessment and evaluation system is an important unignorable factor, but so far, there has not had a systematic study on the assessment and evaluation system of this course. Thus, this article is going to begin with sorting out the internal deficiencies of the current assessment and evaluation system of "athletic physiology", make reflection on the theory of this course, combine the advantages of the educational evaluation, employ the quantitative method and qualitative method comprehensively, set up an assessment and evaluation system with combination of "theory, design and application", and pursue, to the largest extent, scientificalness, maneuverability and effectiveness of the system, which is of great significance to improve the teaching quality. 


\section{Reflection on the Traditional Assessment and Evaluation System of “Athletic Physiology"}

The performance of "athletic physiology" mainly includes two parts in the traditional educational evaluation system, namely, the ordinary performance of students and the final exam score of students. It has been a long time that influences of exam-oriented education and dependence of universities on the means and methods of all aspects of teaching evaluation in middle schools have made the content, means and functions of the evaluation system of learning effects of students have a variety of drawbacks (Liu Jun, 2009) The traditional assessment and evaluation system has restrained development forward of the teaching quality of the course of "athletic physiology".

\subsection{Narrowness of Evaluation Content --- Mere Emphasis on Assessment of Theory}

The evaluation system of sports curriculum is a means to facilitate teaching. Nonetheless, for quite a long time, learning evaluation content of sports curriculum in regular institutions of higher learning is single and emphasizes too much on objective and quantified evaluation (Hang Lanping et al., 2006). For the time being, a large majority of sports colleges and departments still regard the basic theory exam as a primary means to assess "athletic physiology". However, assessment on design and application of experiment, fitness and training plans is either devoid or occupies a low proportion in the total score of the curriculum. This seriously affects students' concentration on and grasp of the practical teaching aspects. Yet, practice is exactly the key to examine whether students employ athletic physiology knowledge. We can imagine the teaching effect if students merely cram for the coursebook. In addition, the traditional assessment and evaluation system also ignores students' knowledge capacity and quality in terms of expansion level.

\subsection{Monotony of Evaluation Means --- Exam Score as the Major Evaluation Proof}

In the traditional evaluation system, to some extent, assessment of "athletic physiology" still employs the disciplinary exam-oriented education evaluation method which lacks scientificalness. Students have no idea what kind of standard and requirement they should achieve in the process of assessment. As a result, they have no other choice but to mechanically memorize the basic theory and blindly pursue a high exam score. Likewise, teachers still remain at the level of discrimination and selection function in their positioning of evaluation on students' curriculum and they pay too much attention to students' exam performance and deem their score as the unique scale in measuring students' grasp of knowledge and skills, ignoring personality development of different students.

\subsection{Imbalance of Evaluation Weight --- Irrational Evaluation Index Proportion}

Considering the traditional assessment and evaluation system of "athletic physiology", as a result of narrowness of the evaluation content, the quantity of indexes that can be evaluated is reduced and comprehensive factors are lacking. Design of a scientific evaluation system should include multiple indexes of the basic level (theoretical knowledge, experimental aspect and practical aspect) and expansion level and then classify different evaluation proportions according to different content, namely, weight. Since the evaluation mode in the traditional assessment and evaluation system is monotonous or pays too much attention to the basic theory, that leads to irrational weight in the proportion of the evaluation content.

\subsection{Single Evaluation Subject --- Based on Assessment by Teachers}

Evaluation should involve multiple subjects since this helps to evaluate students from multiple aspects and angles and from different aspects of the same student so as to discover their advantages or disadvantages. If students acquire pertinent teaching, this can make the evaluation more comprehensive, scientific, fair and justified. However, it is exactly this fact that the traditional assessment and evaluation system of "athletic physiology" ignores. In the traditional assessment and evaluation system, both formulation and implementation of the evaluation indexes is completed by the teachers who not only teach but also evaluate. The traditional assessment and evaluation system depends largely on teachers and ignores self-evaluation and mutual evaluation of students, so it has great limit (Yang Ling, 2007). Students are those who are administered and the object of evaluation, so they can only accept guidance and evaluation of students. As a result, it is unavoidable that the evaluation result is subjective and one-sided.

\subsection{Deterioration of Evaluation Function --- Based on Summative Evaluation and Lacking in Process Evaluation}

The traditional evaluation system excessively focuses on the teaching activity results of students and their acquisition of knowledge and skills, but ignores students' enthusiasm in participation in the process of learning and their efforts and ignores a dynamic evaluation on development, change and growth of students (Zhang Xiaofeng, 2008). Specifically speaking, the traditional assessment and evaluation system of "athletic physiology" only focuses on students' memory in theory, but ignores students' capacity in knowledge transfer and application. Some students may not take the class seriously, but they have a good memory, so they can get a high mark by cramming for the coursebook prior to the exam. By contrast, some students have high enthusiasm in participation in the process of learning and they have made great efforts, but they have not got a high mark by mechanically memorizing the 
coursebook. The above is the typical case of evaluation that does not evaluate the process of students' development, change and growth, as a result of which the result is unjustified.

\section{Ideological Basis for Reconstruction of the Assessment and Evaluation System of "Athletic Physiology” --- Changing the Concept of Teaching}

Assessment and performance evaluation is the final important aspect in teaching of "athletic physiology". As an important mode in propelling teaching reform, it is not only an effective means to test the quality of teaching, but also a baton and regulator in teaching and an important aspect in educational quality. In order to carry out the teaching syllabus of 'athletic physiology" with high quality and ensure successful ongoing of teaching of the curriculum, it is necessary to update concepts, changes ideas and highlight the important role of athletic physiology course in talent cultivation in sports major in universities in the process of learning (Cao Shiyun, 2007). It is quite necessary to reconstruct the assessment and evaluation system of the curriculum according to the disciplinary feature of strong practicality.

First of all, reform and reconstruction of the assessment and evaluation system of the course of "athletic physiology" is to change the concept of teaching, namely, designing the teaching goal of this course according to requirements of the teaching syllabus. In "Taxonomy of Educational Objectives", Bloom classified educational objectives into knowledge, comprehension, application, analysis, synthesis and evaluation, etc. (Zhu Lin, 2008). The assessment objective determines whether the content of assessment, assessment mode and means comply with the purpose and requirement of assessment and reflects different educational guidance ideas. Thus, the teaching goal of the course can only be fulfilled by means of designing the assessment objective of the course "athletic physiology" on the basis of correctly comprehending "undergraduate talent cultivation program in sports major".

Curriculum syllabus of "athletic physiology" in undergraduate talent cultivation program in sports major definitely points out, athletic physiology is a branch of physiology and is an applicable discipline that is young and rapid in development and presents the feature of multidisciplinary overlapping and intersecting. Athletic physiology mainly studies reaction and adaptation of human body to athletics. This course expounds the effect of physical sports on health by means of discussing influences of physical sports on development changes of functions of human body so as to facilitate the nationwide fitness, strengthen national physical quality and enhance the healthy level of the citizens. It grasps the physiological functions and features of different kinds of athletes and organizes training in a scientific way by means of studying the physiological principle of athletic training so as to promote implementation of the plan of "adding luster to the Olympic Games". It scientifically organizes sports teaching by means of studying the physiological basis of sports teaching so as to finish education with record of formal schools at all levels at present and meanwhile, promote benign growth of both the body and mind of young people. Thus, the assessment and evaluation system of "athletic physiology" that has been newly established should correspond with anticipation of the teaching content on the teaching activity results at all stages and has to be subject to the overall goal of teaching of this course, which should not only reflect that athletic physiology can both serve for competitive training and can guide fitness activities of the public. Therefore, assessment should not be regarded as test on recitation of the basic theory. Instead, it should concentrate on impartation of methods, flexible application and enlightenment of wisdom so as to change the traditional assessment goal of memorizing point of knowledge. Establishment of specific assessment and evaluation system can proceed according to the requirement of combination of "theory, design and application”, including understanding and grasping basic scope, basic principle, basic method, designing of athletic training plans or program of fitness guidance and the capacity of application in practice, etc.

In short, the goal of establishing the assessment and evaluation system of "athletic physiology" with combination of "theory, design and application" is to require teachers to teach students a kind of thinking method. On one hand, it emphasizes on learning through questions and regards questions as the motive and starting point of learning and as the major clue that runs through the learning process. On the other hand, it generates questions by learning and regards the learning process as a process of discovering problems, proposing problems, analyzing problems and resolving problems (Liu Zhiyun, 2006). What this system pursues is not to ask students to mechanically memorize a theory without a single mistaken word, but to encourage students to give full play to their subjective initiative in a relatively open teaching environment and to strengthen their capacity of digesting and applying knowledge in athletic physiology.

\section{Objective Requirements in Reconstruction of the Assessment and Evaluation System of "Athletic Physiology” --- Following Basic Principles}

The goal of assessment determines the content and scope of assessment. According to the goal of assessment of "athletic physiology", so far as the exam pattern is concerned, the assessment and evaluation system framework of this curriculum should follow the following principles. 


\subsection{The Principle of Combination of Syllabus with Basis}

A proposition should closely center around the teaching material and teaching syllabus to select. Teaching material is an instrument for students to acquire knowledge, edify their sentiment and cultivate their capacity; while teaching syllabus is the basis for carrying out a teaching plan and is also the basis for teachers to teach and implement an exam proposition. In the process of teaching, if teachers fail to grasp the principle of entirety and comprehensiveness of the curriculum of "athletic physiology" and give prominence to the feature of strong applicability, they are likely to be trapped in the contradiction of fewer teaching hours and much teaching content, which is specifically manifested as quite detailed explanation of knowledge point but less combination with athletic practice. Specifically speaking, in design of the assessment and evaluation system of the curriculum, it is many meticulous knowledge points and many questions with strong memory. Quite a lot of students complain that they find out the entire textbook is all emphasis in their review and they have no way to memorize the entire textbook. This indicates that most of the assessment content is to memorize the knowledge points, but not the capacity of analyzing problems and resolving the problems. The so-called principle of combination of syllabus with orientation is to regard teaching syllabus as the syllabus and the teaching material as the basis, apprehend the syllabus, center around the teaching material and highlight emphasis and major content. In terms of design of the system, it is necessary to grasp major content and it is avoided to conceal highlighting the emphasis with the excuse of broad coverage scope.

\subsection{The Principle of Appropriate Difficulty}

The assessment and evaluation system of "athletic physiology" should fully reflect the difficulty of the function of taking an exam and also the goal of achieving assessment by means of taking an exam. Applicability of "athletic physiology" is strong and its goal of assessment is distinguished from other courses. Students' capacity of grasping and applying this curriculum has a great connection with their employment in the future. Thus, if the difficulty of assessment is too great which leads to failure or low passing rate of a large number of students, this will not only deviate from the teaching goal of "athletic physiology", but is also likely to make the students have the psychology of fear, boredom or confrontation. If the assessment is too simple, it might make the students have the psychology of ignorance. As a result, they may not take this curriculum seriously in the class and the exam will not be able to play its functions of evaluation, judgment, feedback and incentive. In addition, all the assessment content should not have too much homogeny and should be distinguished in terms of difficulty and simplicity so as to enhance the discrimination of the total score and this requires to make a qualitative analysis on all test questions.

\subsection{The Principle of Synchronism}

Updating of teaching content and assessment content of the curriculum of "athletic physiology" should be in harmony with design of the assessment. From the perspective of Marxism, all the cognition of human kind was generated under a certain historical condition and had its limitation. The thinking of human kind could only know about the world with a profound message and comprehensively by accompanying the path of summarizing practical experience and scientific achievement and this process was endless. There is no exception with athletic physiology. It will update the content with continuous development of practice, improve its application pattern and continue to propose new problems and resolve the problems, which is a developing but open scientific system. Hence, the teaching content of the curriculum of "athletic physiology" should follow closely development of practice for any change and make adjustment and updating in due time and sufficiently reflect the characteristics of the times, introduce the latest practical research to students. Extensive reading may provide students with a variety of choices, broad students' vision of field and train students' capacity of discovering, reflecting, synthesizing and resolving a problem in a comprehensive way (Wang Ping, 2005). Correspondingly, design of the assessment and evaluation system of the curriculum of "athletic physiology" should also keep close pace with the times, supplement the latest research achievements in due course, closely link up with the athletic practice and focus on hot issues and difficult issues. Only if the teaching content, assessment content and evaluation content are unanimous with each other and fully reflect practicality, applicability and creativity of the curriculum of "athletic physiology", can this curriculum arouse students' interest and concentration and can they pay attention to it and take it seriously so as to improve the effectiveness of the curriculum.

\subsection{The Principle of Guiding}

Design of the assessment and evaluation system of the curriculum of "athletic physiology" should not merely guide students to apply mechanically the textbook, but should also direct them to start out from reality and to pay attention to connection of theory with reality. Examples in practice are of authenticity and resolution of a problem proposed not only requires new knowledge, but also calls for application of the basic theory. This is not to require the teachers to designate a certain kind of teaching material and to let students comprehend and memorize this material, but to 
present, guide and summarize the problems that need to be learnt and inquired so as to encourage students to probe independently into the method of resolving the problem and come to a conclusion (Huo Yiping, 2002). Teachers should lose no time to integrate classroom teaching with experiment, practice and scientific research in the new assessment and evaluation system to make an overall assessment on students, and guide students enter the academic threshold and to participate in the scientific research, which is an important measure to cultivate talents with high quality and high level who are able to satisfy with demands of the society and who are able to suit with and promote social progress and development and which is also the obligation and responsibility of each university teacher. In the process of teaching the curriculum of "athletic physiology", teachers should keep a close look on the development tendency of the discipline, bring in new viewpoints and new knowledge in due course. In this way, teachers may play an obvious important role in terms of highlighting the practical characteristics of teaching, performing the applicable functions of teaching and cultivating students' actual capacity, etc., and provide benign guidance for university students.

\section{Realistic Approach to Reconstruction of the Assessment and Evaluation System of "Athletic Physiology" --- Combination of "Theory, Design and Application"}

Different assessment modes may also affect students' enthusiasm and effect in learning the curriculum of "athletic physiology". It was discovered in a survey on the assessment and evaluation systems of different physical faculties and departments that, different universities adopted different modes. Some universities specified that they established the "new concept" of exam at ordinary times, increased, on a large margin, its proportion in the total score and began to bring in the mechanism of exemption from exam. Some universities proposed adopting the examination mode with combination of "whole" and "individual". Some other universities applied practice of students into the assessment and evaluation system, etc. Generally speaking, almost all the assessment modes adopted in universities are two stages, namely, combination of performance at ordinary times and final exam score. This sort of traditional assessment and evaluation system not only focuses on the learning process of students, but also highlights the learning result, which, theoretically, is scientific, but often has a lot of problems in the actual operation. For example, the performance at ordinary times occupies a low weight, in which the classroom evaluation is not sufficiently scientific, ignores experimental performance and students mechanically memorize the textbook in the closedbook exam, blindly copy the textbook in the open-book exam and plagiarize and piece together others' writings in writing a thesis, etc. especially the phenomenon is serious that teachers randomly change the performance of students at ordinary times. Thus, the curriculum of "athletic physiology" should adopt the system with combination of "theory, design and application" to make an assessment and really set up a sort of comprehensive assessment and evaluation system that is able to combine effectively the performance of students at ordinary times and their final exam performance.

\subsection{Assessment with Emphasis on Performance at Ordinary Times}

As a basic curriculum in physical department, the developmental trend of "athletic physiology" has converted from a pure basic theoretical course to applicable course and its application in practice has received more and more concentration. As a matter of fact, the pattern of taking an exam and the mode of examination of knowledge point are unable to accurately and completely test the teaching situation between teachers and students. Hence, it seems more rational to make an assessment by taking into consideration the performance of students at ordinary times. Specifically speaking, the first thing to do is to enhance appropriately or, on a large margin, the proportion of performance of students at the ordinary times. In assessment of the curriculum of "athletic physiology", universities adopt the assessment model of standard nomenclature, unified reading of the examination papers and separation of taking an exam and teaching and tend to use the closedbook exam to measure students' grasp of the curriculum. The performance of students at ordinary times only accounts for $20 \%$ or so of the total score. Since the weight is relatively low, it is often that students ignore the performance at ordinary times and do not take it seriously. They tend to cram for the textbook prior to the exam and even cheat in the exam. In order to change this phenomenon that "the exam decides all", it is necessary to increase the weight of performance at ordinary times which should be increased to $60 \%$ and even $70 \%$. Then, it is necessary to set up a scientific method of assessment for performance at the ordinary times. The performance at the ordinary times should be rational and justified, which may record students' performance inside and outside the class, such as, checking on their work attendance, their homework, discussion, experiment and thesis, etc., and give the feedback to students in due course. If the homework at the ordinary times can really reflect the learning performance, learning life and practical capacity of students at the ordinary times, it should be taken into consideration (Zuo Hua, 2008). In this way, students are able to accurately grasp their learning situation and if there is any disadvantage, they should improve it in time, which can also prevent teachers from randomly changing the performance of students at the ordinary times as a result of the subjective factors. 


\subsection{Assessment Strengthening Application of Practice}

Social practice is an indispensable teaching aspect in the theoretical education of Marxism. Therefore, it seems quite important to bring the practical teaching achievements of students into the assessment and evaluation system of the curriculum and formulate relevant assessment and evaluation mode. Practice is the foundation of athletic physiology and foundation of teaching of this curriculum and is also the source for knowledge in athletic physiology. The goal of practice of "athletic physiology" is to facilitate students' comprehension and conversion of knowledge, learning of scientific method, cultivation of scientific spirit and improvement of creative capacity. For the time being, the phenomena of inappropriate recognition, impressed hours of learning, insufficient funds, implicit assessment standard and bad practical achievement, etc., exist in practical teaching of the curriculum of "athletic physiology" in universities. Thus, the priority to strengthen assessment of practical teaching is to set up a security mechanism for practical teaching and ensure implementation of class hour, credit hour and special funds for practical teaching of "athletic physiology". Otherwise, there is no way to talk about practical teaching. Secondly, it is necessary to carry out the assessment standard for practical teaching in accordance with the organizational aspect of practical teaching. All the following content should be brought into the assessment system to carry out a standard of evaluation: selection of practical program, organization of students, design and implementation of the practical program and summary and evaluation of practical achievement (there are two kinds of achievement. One kind is visible achievement, including students' familiarity with use of the experimental instrument and their grasp of the experimental principle and experimental method, etc. The other kind is invisible achievement, such as, report of practice and thesis, etc.). The curriculum of "athletic physiology" is a discipline with strong practicality and only when the theory and practice are combined in an organic way, is it likely to foster talents with capacity and that are favored by the society. Either laboratory and playground or exercitation base are all our occasions for practice. Through experiment and practice, we assess students' application and transfer of theoretical knowledge, test students' learning effect, improve their operation ability and diminish the gap between the universities and the society, which plays a positive thrusting role for students' adaptation to the society after graduating from the university.

\subsection{Enriching the Evaluation Subject and Improving the Reliability of Final Exam}

Participation of both of the two parties involved in teaching can make the evaluation more comprehensive, scientific, justified and fair. For instance, a certain proportion of self grading can be set in the total score of the curriculum and this proportion can be set at $5 \%$ to $10 \%$ so as to mobilize students' enthusiasm in participating in learning. Or students may grade a score for their performance at the ordinary times according to the process of their learning and if this score is close to the one graded by teachers, it indicates that the overall evaluation is rational. However, if the two scores have too large a gap, students may put forward different opinions and then re-examination can be made according to their performance that is recorded by teachers, which is also helpful to find out students' disadvantages in the process of learning. On the other hand, the score of the final exam is mainly determined by the score of assessment conducted at the end of the school semester. A large majority of students do not recognize or are disappointed at the closedbook exam mode in the assessment at the end of the school semester and they hold the opinion that closedbook exam is not able to correctly evaluate the learning situation of a student in participating in this curriculum. However, considering the features of students majoring in sports and the foundation of the theoretical knowledge, it is not a proper time to completely cancel the closedbook exam pattern and to make an assessment at the end of the semester by means of thesis and design of training program, etc. Thus, the primary problem at present is to enhance the reliability of final exam. The first thing to do is to change the specific assessment mode and to develop from single closedbook test to exam of diversification, such as, combination of open-book exam and closedbook exam, combination of oral test and written test and combination of subject research and classroom exam, etc. Secondly, it is to reform the question types in the exam. Teachers should try to avoid or totally avoid the short answer question, choice question and fill in the blanks question that mainly regard memory of knowledge points as the goal of assessment. Instead, they should choose some question types that are able to sufficiently play the subjective initiative of students and cultivate students' creativity spirit and capacity of independent analyzing and resolving an actual problem, such as, discrimination question, analysis question and application question, etc.

\section{Concluding Remarks}

There are various methods of assessment and evaluation, but whatever method we adopt, the first thing to do is to ensure authenticity, scientificalness and rationality of the content of evaluation, effectiveness of evaluation means and justice and fairness of evaluation result and base on students orientation. However, evaluation should neither blindly pursue quantification nor pursue meticulousness, which might cause the two parties involved in evaluation to rush about for the result of evaluation and lead to a sort of vicious circle. Reform on the assessment and evaluation 
system of the current curriculum of "athletic physiology" is to design and set up a sort of new assessment and evaluation system that can not only satisfy students' demands and mobilize students' interest in learning, but can also improve the learning effect and facilitate students' comprehensive development, which is also an indispensable important component of teaching reform in the curriculum of "athletic physiology". For the time being, in order to adapt to the developmental trend of teaching reform, we have made reform and explorations on terms of teaching method, teaching content and compilation of teaching material, etc., and have achieved certain achievement. The developmental trend of the assessment and evaluation system of the curriculum of "athletic physiology" will be to set up a scientific evaluation system that suits with the cultivation goal of sports department in universities and to reform the traditional mode. When teachers design a specific exam and evaluation program, they are supposed not only to test the knowledge points of students, but also to examine the capacity of students' in applying knowledge they have learnt, their practical capacity and participation in the teaching process, etc. Students can also have such a feeling that this kind of assessment and evaluation system can not only help improve their capacity in applying knowledge they have learnt, their self-learning capacity and practical application capacity, but can also greatly facilitate formation of their capacity of self-evaluation and capacity in analyzing a problem and resolving the problem.

\section{References}

Cao, Shiyun. (2007). Practice and Exploration of Construction and Reform of the Course of "Athletic Physiology" in P. E. College in Higher Normal Universities[J]. Heilongjiang Researches on Higher Education, 7, 105-107.

Hang, Lanping et al. (2006). Research on the Effects of "Multi-dimensional Models of Physical Education" on Realizing Multi-dimensional Purposes of P.E. Curriculum and Its Practice[J]. Journal of Beijing Sport University, 7.

Huo, Yiping. (2002). Inquiry Learning --- Experiment and Exploration. [M] Nanjing: Guangxi Education Publishing House, 119.

Liu, Jun (2009). Investigation of New Examination for Modern Chinese literature[J]. Journal of Social Science of Jiamusi University, 27(2):134-136.

Liu, Zhiyun (2006). Discussion on Relationship Between Research-based Teaching and Research-based Learning in Universities[J]. China University Teaching, 2, 24-27.

Wang, Ping (2005). Re-understanding of Characteristics of Research Based Teaching in Universities[J]. Journal of Guangxi College of Education, 6, 9-10.

Yang Ling (2007). Factors influencing college elective P. E class effects[J]. Journal of Wuhan Institute of Physical Education, 8.

Zhang, Xiaofeng (2008). General Principles in Designing of Index System of Evaluation on Quality of Internship and Training of Vocational Students[J]. The Science Education Article Collects, 9, 43.

Zhu, Lin (2008). Theory of Taxonomy of Educational Objectives by Bloom[J]. Cultural Journal, 1, 115-121.

Zuo, Hua (2008). Establishing Scientific and Rational Students Evaluation System --- Brief Discussion on How to Evaluate Students in Quality-oriented Education[J]. New Perspectives Quarterly, 9, 97.

\section{Authors}

Liu Qian was born in Sichuan, China in 1980. He received his M.A. Degree in Science of Sports Training from Chengdu Sport University, China in 2006. He is currently a lecturer in the Department of Sports, College of Arts and Sports, Sichuan Agricultural University, Sichuan, China. His research interests include sports training and sports science. 